\title{
A Study of Comparison of Post-Operative Analgesia after Single-Shot Caudal Epidural Block Using Bupivacaine with or without Clonidine in Children
}

\author{
Shakti Singhal', Shakti Datt Sharma ${ }^{2}$, Vandana Chugh $^{3}$, Gunjan Aggarwal $^{4}$ \\ ${ }^{1}$ Senior Resident Anesthesiology, Dr Baba Saheb Ambedkar Hospital and Medical College, Delhi. \\ ${ }^{2}$ Anaesthesiology, Senior Administrative Grade Medical Officer, Dr Baba Saheb Ambedkar Hospital \\ and Medical College, Delhi. \\ ${ }^{3}$ Anesthesiology, Specialist Anaesthesia, Dr Baba Saheb Ambedkar Hospita and Medical College, Delhi. \\ ${ }^{4}$ Pathology, Senior Resident Anesthesiology, Dr Baba Saheb Ambedkar Hospital and Medical College, Delhi. \\ DOI: https://doi.org/10.24321/2349.7181.201807
}

\begin{abstract}
Introduction: Lower abdominal surgeries are one of the most frequently performed surgeries in the pediatric age group. A large number of these operations are done as day-care procedures.

Caudal block is one of the most common regional anesthetic techniques in children being used to supplement general anesthesia for a wide variety of sacral-segment surgery. The local anesthetics currently in use are safe and their pharmacological effects have been well evaluated. There is no fear of neurological sequelae as in the past.

Several studies have demonstrated that Clonidine added to the local anesthetic in caudal block both enhances and prolongs the analgesia produced by the block without the unpleasant or hazardous sideeffects associated with the use of other adjuvant drugs like opioids, epinephrine and some newer adjuvants like neostigmine and dexmedetomidine. Our study aimed to evaluate the efficacy of single-dose caudal epidural Clonidine in prolonging the post-operative analgesia when mixed with Bupivacaine in children.

Materials and Methods

Sixty children of ASA I and ASA II physical status, between 1 and 12 years of age, who underwent elective lower abdominal surgeries, were randomly divided into two groups $B(N=30)$ and $C(N=30)$. All the children were administered general anesthesia. After induction, a single-shot caudal block was administered using $0.25 \%$ Bupivacaine (group B) and $1.5 \mathrm{mg} / \mathrm{kg}$ of Clonidine hydrochloride (group C). Vital monitoring was done intraoperatively as per institutional protocol. Post-operative monitoring was done in the post-anesthesia care unit (PACU) for 2-3 hours and in the ward for next 24 hours. Data with respect to duration of surgery, duration of pain-free period, time to void and any other complications was compiled. The final results of the study were tabulated and analyzed for significance using standard statistical techniques (unpaired t-test).
\end{abstract}

Corresponding Author: Dr. Shakti Datt Sharma, Dr Baba Saheb Ambedkar Hospital and Medical College, Delhi.

E-mail Id: pushkrit@gmail.com

Orcid Id: https://orcid.org/0000-0002-3471-3573

How to cite this article: Singhal S, Sharmal SD, Chugh V et al. A Study of Comparison of Post-Operative Analgesia after Single-Shot Caudal Epidural Block Using Bupivacaine with or without Clonidine in Children. J Adv Res Med 2018; 5(2): 6-12. 
Results

This study was undertaken to evaluate the efficacy of Clonidine in prolonging post-operative analgesia of Bupivacaine when given caudally in 60 children undergoing lower abdominal surgeries. The duration of pain-free period with caudal Bupivacaine with Clonidine (group C) is significantly longer than caudal Bupivacaine (group B). The duration of pain relief was 20.4 hours in group C as compared to 14.2 hours in group $B$. This is statistically significant $(p<0.05)$.

\section{Conclusion}

We conclude that adding Clonidine $1.5 \mathrm{mg} / \mathrm{kg}$ to Bupivacaine $0.25 \%$ for caudal anesthesia in children undergoing lower abdominal surgeries enhances and prolongs postoperative analgesia compared to caudal Bupivacaine $0.25 \%$ alone. Clonidine may be the drug of choice to prolong the duration of caudal anesthesia provided by a single injection in children.

Keywords: Caudal epidural block, Bupivacaine Clonidine

\section{Introduction}

Pain is a protective mechanism designed to alert the body to potentially injurious stimuli. The International Association for the Study of Pain has defined pain as 'an unpleasant sensory and emotional experience, associated with actual or potential tissue damage'. ${ }^{1}$

The alleviation of pain has been the focus of continuing human effort. However, it has been recognized for some time that the management of acute pain, especially postoperative pain, has been consistently inadequate. The situation in children has been even worse; children have long been under-medicated for acute pain. ${ }^{2}$

Caudal block is one of the most common regional anesthetic techniques in children being used to supplement general anesthesia for a wide variety of sacral-segment surgery. During the second half of the 1980s, neuroaxial administration of opioids became en-vogue in adult anesthesia and Krane and colleagues in 1988 published dose-response data for morphine as an adjunct to caudal anaesthesia in children. ${ }^{3}$ Soon after this, the successful use of both racemic ketamine and Clonidine was described. ${ }^{4}$ During the following years, a large number of studies on the adjunct use of these drugs in caudal anaesthesia have been published and this literature has recently been the focus of a number of review articles. ${ }^{5-7}$

The use of adjuvants in caudal block has several advantages. Several studies have demonstrated that Clonidine added to the local anesthetic in caudal block both enhances and prolongs the analgesia produced by the block without the unpleasant or hazardous side-effects. ${ }^{8,9}$

\section{Aims and Objectives}

The aims of this study were:

- To clinically evaluate the efficacy of caudal epidural
Clonidine in prolonging the post-operative analgesia when mixed with Bupivacaine in children;

- To compare the post-operative pain-free duration and side effects of Bupivacaine with or without Clonidine.

\section{Materials and Methods}

After institutional ethical committee approval and written informed consent from the patients, sixty children of ASA I and ASA II physical status, between 1 and 12 years of age, posted for elective lower abdominal surgery were included in the study.

Study Design: Prospective randomized double blind.

\section{Sample Size: 60}

\section{Exclusion Criteria}

- Children with known allergy to local anesthetics

- Bleeding diathesis

- Aspirin ingestion in the preceding one week

- Presence of septic focus on the skin over the caudal region

- Any bony abnormality of the sacrum

- Pre-existing neurological disease or ASA III

The children were randomly divided into two groups of 30 each.

Group B $(\mathrm{n}=30)$ received only $0.75 \mathrm{~mL} / \mathrm{kg}$ of $0.25 \%$ Bupivacaine.

Group C $(\mathrm{n}=30)$ received Inj. Clonidine $1.5 \mu \mathrm{g} / \mathrm{kg}$ in addition to $0.75 \mathrm{~mL} / \mathrm{kg}$ of $0.25 \%$ Bupivacaine.

\section{Procedure Methodology}

After careful pre-anesthetic checkup and routine investigations, and informed consent, the patients were premedicated inj. Glycopyrollate 5-10 $\mathrm{\mu g} / \mathrm{kg}$ intramuscularly 
and an intravenous line was started inside the operating room. Thereafter, the patients were induced with inj. Thiopentone 5-6 mg/kg IV+inj. Vecurenium $0.1 \mathrm{mg} / \mathrm{kg}$ and ventilated for $3 \mathrm{~min}$. Patients not having intravenous access were induced with inhalational agent Sevoflorane+O2+N2O and intravenous line was taken. Inj. Vecuronium $0.1 \mathrm{mg} / \mathrm{kg}$ was used to facilitate intubation. Endotracheal tube was used to maintain the airway. Maintenance of anesthesia was done with Oxygen+Nitrous oxide+Isoflurane. Inj. Vecuronium was used for muscle relaxation. Caudal block was performed after induction and before the start of surgery, using standard techniques. The children were randomly divided into two groups of 30 each with regards to drug used for caudal block.

Group B $(n=30)$ received only $0.75 \mathrm{~mL} / \mathrm{kg}$ of $0.25 \%$ Bupivacaine.

Group C ( $\mathrm{n}=30$ ) received inj. Clonidine $1.5 \mu \mathrm{g} / \mathrm{kg}$ in addition to $0.75 \mathrm{~mL} / \mathrm{kg}$ of $0.25 \%$ Bupivacaine.

Intraoperatively, the patient was monitored using standard monitoring, i.e., systolic blood pressure (non-invasive), pulse-oximetry, heart rate and ECG during the course of surgery. Intravenous fluids were given as per requirement. The neuromuscular blockade was reversed with inj. neostigmine $50 \mu \mathrm{g} / \mathrm{kg}$ and inj. Glycopyrollate at the end of surgery. Post-operative monitoring was done in the post-anesthesia care unit (PACU) for 2-3 hours and in the ward using a standard proforma for next 24 hours.

The assessment of pain relief was done by using an objective pain score (Hannallah-Broadman). In addition, the following parameters were noted:

- Duration of surgery

- Duration of pain-free period

- Time to void

- Any other complications namely - nausea, vomiting, motor weakness, respiratory depression, sedation, hypotension, and bradycardia
At the onset of pain, rescue analgesia was given as appropriate and the total duration of analgesia was noted. The final results of the study were tabulated and analyzed for significance, using standard statistical techniques (unpaired t-test).

\section{Results}

There was no significant difference between the two groups with respect to age (years), weight and duration of surgery. Two independent sample t-tests were used for comparison of Bupivacaine group and Bupivacaine plus Clonidine group with respect to systolic blood pressure (SBP) $(\mathrm{mmHg})$, diastolic blood pressure (DBP), heart rate, and pain score. There was significant difference between Bupivacaine group and Clonidine group with respect to systolic blood pressure (SBP) at post-caudal $10^{\text {th }} \mathrm{min}, 20^{\text {th }} \mathrm{min}$, $\mathrm{p}$-value $<0.05,30^{\text {th }}$ min, $60^{\text {th }}$ min and $90^{\text {th }}$ min (Table 1). There was significant difference between Bupivacaine group and Clonidine group with respect to diastolic blood pressure (DBP) at post-caudal $10^{\text {th }} \mathrm{min}, 20^{\text {th }} \mathrm{min}, 30^{\text {th }} \mathrm{min}, 60^{\text {th }} \mathrm{min}, 90^{\text {th }} \mathrm{min}, 120^{\text {th }} \mathrm{min}$ and post-op $1^{\text {st }}$ hour, $2^{\text {nd }}$ hour, $3^{\text {rd }}$ hour, $6^{\text {th }}$ hour, $9^{\text {th }}$ hour to $24^{\text {th }}$ hour except $21^{\text {st }}$ hour, $p$-value $<0.05$ (Table 2 ). There was significant difference between Bupivacaine group and Clonidine group with respect to heart rate at post caudal $10^{\text {th }} \mathrm{min}, 20^{\text {th }} \mathrm{min}, 30^{\text {th }} \mathrm{min}, 60^{\text {th }} \mathrm{min}, 90^{\text {th }} \mathrm{min}, 120^{\text {th }} \mathrm{min}$, after extubation and post-op $1^{\text {st }}$ hour, $2^{\text {nd }}$ hour, $3^{\text {rd }}$ hour, $6^{\text {th }}$ hour, $9^{\text {th }}$ hour to $24^{\text {th }}$ hour, p-value $<0.05$ (Table 3 ). There was significant difference between Bupivacaine group and Clonidine group with respect to objective pain score at after extubation and post op $3^{\text {rd }}$ hour, $6^{\text {th }}$ hour, 9 hour to $21^{\text {st }}$ hour. p-value $<0.05$ (Table 4). Mann-whitney test (Table 5) $p$-value $<0.05$ showed there was significant difference between the Bupivacaine group and Clonidine group with respect to sedation score at after extubation, post-op $1^{\text {st }}$ hour to $9^{\text {th }}$ hour and post-op $15^{\text {th }}$ hour, $18^{\text {th }}$ hour and $24^{\text {th }}$ hour. Two independent sample t-test $p$-values $<0.05$ showed there was significant difference between the two groups with respect to time at analgesia required (Table 6). 
Table 1.Comparison of Bupivacaine Group and Bupivacaine Plus Clonidine Group with respect to Systolic Blood Pressure (SBP) (mmHg)

\begin{tabular}{|c|c|c|c|}
\hline \multirow{2}{*}{ SBP at } & \multicolumn{2}{|c|}{ SBP (Mean \pm SD) } & \multirow{2}{*}{ p-value } \\
\cline { 2 - 3 } & Bupivacaine & Clonidine & \\
\hline Baseline & $93.53 \pm 5.19$ & $93.73 \pm 4.83$ & 0.878 \\
\hline After induction & $87.53 \pm 3.10$ & $88.33 \pm 3.37$ & 0.342 \\
\hline Post caudal at 10th min & $87.73 \pm 5.24$ & $84.40 \pm 3.98$ & $0.007^{*}$ \\
\hline at 20th min & $84.67 \pm 2.99$ & $78.60 \pm 3.11$ & $<0.001^{*}$ \\
\hline at 30th min & $88.67 \pm 6.04$ & $85.33 \pm 5.36$ & $0.027^{*}$ \\
\hline at 60th min & $85.67 \pm 1.97$ & $80.33 \pm 4.24$ & $<0.001^{*}$ \\
\hline at 90th min & $85.60 \pm 1.98$ & $82.40 \pm 5.29$ & $0.003^{*}$ \\
\hline at 120th min & $88.29 \pm 6.46$ & $86.14 \pm 4.87$ & 0.331 \\
\hline after extubation & $88.73 \pm 6.38$ & $90.20 \pm 3.42$ & 0.273 \\
\hline Post-op 1st hour & $91.20 \pm 5.03$ & $89.20 \pm 5.70$ & 0.155 \\
\hline 2nd hour & $88.53 \pm 4.73$ & $90.80 \pm 4.69$ & 0.067 \\
\hline 3rd hour & $90.20 \pm 5.29$ & $89.60 \pm 4.88$ & 0.650 \\
\hline 6th hour & $89.93 \pm 5.84$ & $90.27 \pm 4.16$ & 0.800 \\
\hline 9th hour & $90.87 \pm 6.00$ & $89.53 \pm 4.69$ & 0.342 \\
\hline 12th hour & $90.87 \pm 5.53$ & $88.47 \pm 5.30$ & 0.091 \\
\hline 15th hour & $88.67 \pm 5.05$ & $90.53 \pm 6.12$ & 0.203 \\
\hline 18th hour & $90.07 \pm 5.13$ & $89.07 \pm 3.59$ & 0.386 \\
\hline 21st hour & $90.33 \pm 5.51$ & $89.60 \pm 4.15$ & 0.563 \\
\hline 24th hour & $88.27 \pm 5.58$ & $87.80 \pm 6.24$ & 0.761 \\
\hline
\end{tabular}

Table 2.Comparison of Bupivacaine Group and Bupivacaine Plus Clonidine Group with respect to Diastolic Blood Pressure (DBP) (mmHg)

\begin{tabular}{|c|c|c|c|}
\hline \multirow{2}{*}{ DBP at } & \multicolumn{2}{|c|}{ DBP (Mean \pm SD) } & \multirow{2}{*}{ p-value } \\
\cline { 2 - 3 } & Bupivacaine & Clonidine & 0.184 \\
\hline Baseline & $48.47 \pm 5.42$ & $46.93 \pm 3.05$ & 0.516 \\
\hline After induction & $43.20 \pm 3.43$ & $43.73 \pm 2.86$ & $0.025^{*}$ \\
\hline Post caudal at 10th min & $42.93 \pm 4.60$ & $40.73 \pm 2.43$ & $0.029^{*}$ \\
\hline at 20th min & $37.87 \pm 6.85$ & $34.87 \pm 2.34$ & $0.002^{*}$ \\
\hline at 30th min & $46.07 \pm 4.56$ & $42.67 \pm 3.50$ & $0.001^{*}$ \\
\hline at 60th min & $40.93 \pm 3.14$ & $43.67 \pm 2.88$ & $0.006^{*}$ \\
\hline at 90th min & $41.00 \pm 3.18$ & $38.47 \pm 3.75$ & $0.045^{*}$ \\
\hline 120th min & $43.43 \pm 5.05$ & $40.29 \pm 2.02$ & 0.600 \\
\hline After extubation & $43.13 \pm 4.83$ & $43.67 \pm 2.68$ & $0.008^{*}$ \\
\hline Post-op 1st hour & $46.33 \pm 4.84$ & $43.33 \pm 3.50$ & $0.045^{*}$ \\
\hline 2nd hour & $46.67 \pm 5.74$ & $44.33 \pm 2.63$ & $<0.001^{*}$ \\
\hline 3rd hour & $48.13 \pm 5.48$ & $43.53 \pm 2.96$ & $0.022^{*}$ \\
\hline 6th hour & $45.60 \pm 4.05$ & $43.53 \pm 2.56$ & $0.006^{*}$ \\
\hline 9th hour & $46.60 \pm 5.44$ & $43.20 \pm 3.51$ & $<0.001^{*}$ \\
\hline 12th hour & $48.40 \pm 5.95$ & $42.93 \pm 3.43$ & $0.017^{*}$ \\
\hline 15th hour & $45.47 \pm 4.55$ & $42.87 \pm 3.59$ & $<0.001^{*}$ \\
\hline 18th hour & $47.13 \pm 4.89$ & $43.67 \pm 2.47$ & 0.203 \\
\hline 21st hour & $45.13 \pm 4.32$ & $43.93 \pm 2.70$ & $0.021^{*}$ \\
\hline 24th hour & $45.00 \pm 5.40$ & $42.13 \pm 3.82$ & \\
\hline
\end{tabular}


Table 3.Comparison of Bupivacaine Group and Bupivacaine Plus Clonidine Group with respect to Heart Rate (HR)

\begin{tabular}{|c|c|c|c|}
\hline \multirow[t]{2}{*}{ HR at } & \multicolumn{2}{|c|}{ HR (Mean士SD) } & \multirow[t]{2}{*}{ p-value } \\
\hline & Bupivacaine & Clonidine & \\
\hline Baseline & $137.53 \pm 9.13$ & $141.33 \pm 7.78$ & 0.088 \\
\hline After induction & $134.73 \pm 5.74$ & $137.40 \pm 5.54$ & 0.072 \\
\hline Post caudal at 10th min & $122.73 \pm 5.50$ & $117.33 \pm 6.35$ & $0.001^{*}$ \\
\hline at 20th min & $121.47 \pm 6.06$ & $104.53 \pm 7.08$ & $<0.001^{*}$ \\
\hline at 30th min & $120.33 \pm 5.46$ & $94.60 \pm 8.52$ & $<0.001^{*}$ \\
\hline at 60th min & $123.13 \pm 5.27$ & $92.60 \pm 8.73$ & $<0.001^{*}$ \\
\hline at 90th min & $124.60 \pm 5.88$ & $89.43 \pm 14.47$ & $<0.001^{*}$ \\
\hline 120th min & $123.14 \pm 4.20$ & $88.14 \pm 3.46$ & $<0.001^{*}$ \\
\hline After extubation & $137.07 \pm 6.43$ & $113.73 \pm 8.59$ & $<0.001^{*}$ \\
\hline Post op 1st hour & $128.40 \pm 3.54$ & $104.47 \pm 4.97$ & $<0.001^{*}$ \\
\hline 2nd hour & $129.60 \pm 5.29$ & $111.27 \pm 8.57$ & $<0.001^{*}$ \\
\hline 3rd hour & $130.27 \pm 5.06$ & $112.87 \pm 7.57$ & $<0.001^{*}$ \\
\hline 6th hour & $131.13 \pm 3.66$ & $114.13 \pm 6.89$ & $<0.001^{*}$ \\
\hline 9th hour & $132.07 \pm 6.31$ & $115.80 \pm 6.92$ & $<0.001^{*}$ \\
\hline 12th hour & $131.13 \pm 3.66$ & $121.00 \pm 5.32$ & $<0.001^{*}$ \\
\hline 15th hour & $129.13 \pm 4.66$ & $116.87 \pm 7.57$ & $<0.001^{*}$ \\
\hline 18th hour & $129.53 \pm 4.35$ & $123.27 \pm 5.37$ & $<0.001^{*}$ \\
\hline 21st hour & $130.47 \pm 5.19$ & $122.07 \pm 6.29$ & $<0.001^{*}$ \\
\hline 24th hour & $132.53 \pm 5.33$ & $126.40 \pm 4.53$ & $<0.001^{*}$ \\
\hline
\end{tabular}

Table 4.Comparison of Objective Pain Score in Plain Bupivacaine Group and Bupivacaine Plus Clonidine Group

\begin{tabular}{|c|c|c|c|}
\hline \multirow[t]{2}{*}{ Objective Pain Score at } & \multicolumn{2}{|c|}{ Pain Score (Mean \pm SD) } & \multirow[t]{2}{*}{ p-value } \\
\hline & Bupivacaine & Clonidine & \\
\hline After extubation & $1.93 \pm 0.37$ & $0.43 \pm 0.50$ & $<0.001^{*}$ \\
\hline Post-op 1st hour & $0.23 \pm 0.43$ & $0.20 \pm 0.41$ & 0.759 \\
\hline 2nd hour & $0.60 \pm 0.62$ & $0.43 \pm 0.68$ & 0.325 \\
\hline 3rd hour & $0.70 \pm 0.70$ & $0.13 \pm 0.43$ & $<0.001^{*}$ \\
\hline 6th hour & $3.90 \pm 1.09$ & $0.30 \pm 0.53$ & $<0.001^{*}$ \\
\hline 9th hour & $2.77 \pm 0.73$ & $0.17 \pm 0.46$ & $<0.001^{*}$ \\
\hline 12th hour & $2.87 \pm 1.01$ & $0.90 \pm 0.61$ & $<0.001^{*}$ \\
\hline 15th hour & $2.43 \pm 0.86$ & $3.70 \pm 0.70$ & $<0.001^{*}$ \\
\hline 18th hour & $0.90 \pm 0.66$ & $2.03 \pm 0.81$ & $<0.001^{*}$ \\
\hline 21st hour & $1.20 \pm 0.89$ & $0.57 \pm 0.63$ & $0.002^{*}$ \\
\hline 24th hour & $0.60 \pm 0.72$ & $0.60 \pm 0.72$ & 0.996 \\
\hline
\end{tabular}


Table 5.Comparison of Sedation Score in Plain Bupivacaine Group and Bupivacaine Plus Clonidine Group

\begin{tabular}{|c|c|c|c|}
\hline \multirow{2}{*}{ Sedation Score } & \multicolumn{2}{|c|}{ Mean Rank } & \multirow{2}{*}{ p-value } \\
\cline { 2 - 3 } & Bupevacaine & Clonidine & \\
\hline After extubation & 21.00 & 40.00 & $<0.001$ \\
\hline Post-op 1st hour & 22.35 & 38.65 & $<0.001$ \\
\hline 2nd hour & 17.50 & 43.50 & $<0.001$ \\
\hline 3rd hour & 20.05 & 40.95 & $<0.001$ \\
\hline 6th hour & 21.50 & 39.50 & $<0.001$ \\
\hline 9th hour & 21.50 & 39.50 & $<0.001$ \\
\hline 12th hour & 32.43 & 28.57 & 0.395 \\
\hline 15th hour & 43.52 & 17.48 & $<0.001$ \\
\hline 18th hour & 32.82 & 28.18 & 0.295 \\
\hline 21st hour & 15.50 & 45.50 & $<0.001$ \\
\hline 24th hour & 25.50 & 35.50 & 0.001 \\
\hline
\end{tabular}

Table 6.Comparison of Time at Analgesia Required (hour) in Plain Bupivacaine and Bupivacaine Plus Clonidine Group

\begin{tabular}{|c|c|c|c|}
\hline Group & Number of Patients & $\begin{array}{c}\text { Time at Analgesia Required } \\
\text { (Mean } \pm \text { SD) }\end{array}$ & p-value \\
\hline Bupivacaine & 30 & $6.20 \pm 0.76$ & $<0.001$ \\
\hline Bupivacaine plus Clonidine & 30 & $15.00 \pm 0.00$ & \\
\hline
\end{tabular}

\section{Discussion}

This study demonstrates a marked synergistic effect of the combined caudal injection of Clonidine and Bupivacaine in children, resulting in prolongation and enhancement of caudal analgesia post-operatively.

To assess the effects of drugs injected in the caudal epidural space via the sacrococcygeal ligament, it is essential to ensure that no technical failure occurs with the establishment of the caudal block. Caudal block is the most popular neuraxial procedure being used with general anesthesia for analgesia during and after operative procedures involving the lower limbs, perineal region, genitourinary and abdominal surgeries below the umbilicus. ${ }^{10,11}$

As a measure of effectiveness of the caudal block in our study, the inspired isoflurane concentration could be reduced markedly 15 min after skin incision, and throughout the entire operative procedure, no further increase in the concentration of isoflurane was necessary. As with lipophilic opioids, it is possible to achieve analgesia from systemic, epidural or intrathecal administration of Clonidine. However, Clonidine is more potent after neuraxial than systemic administration, indicating a spinal site of action and favoring neuraxial administration. ${ }^{12}$

Clonidine produces analgesia by actions on alpha-2 adrenoreceptors, as shown by partial reversal in humans of epidural Clonidine analgesia and sedation, by the alpha-2 adrenergic antagonist, Yohimbine, although Clonidine's effects on blood pressure and heart rate were not reversed..$^{13}$

The addition of Clonidine ( $1 \mathrm{mg} / \mathrm{kg}$ ) to a caudal epidural solution of Bupivacaine, improved the duration of postoperative analgesia without compromising ventilation. ${ }^{14}$

In our study, caudal Bupivacaine $0.25 \%$ with addition of Clonidine $1.5 \mathrm{mg} / \mathrm{kg}$ provided post-operative analgesia for 15 hours (mean) compared to 6.20 hours with Bupivacaine $0.25 \%$. When adding Clonidine $2 \mathrm{mg} / \mathrm{kg}$ to Bupivacaine $0.25 \%$ for caudal analgesia in children undergoing orthopedic surgery, postoperative analgesia lasted for $9.8 \pm 2.1$ hours compared to $5.2 \pm 1.2$ hours when plain Bupivacaine was used. ${ }^{8}$

We observed a lower incidence of vomiting in the Clonidine group, as compared to Lee and Rubin. ${ }^{8}$ Also no adverse effects of Clonidine administration in the caudal space were observed. There was no incidence of excessive sedation or hypotension, as seen with higher doses of caudally administered Clonidine. One case had bradycardia in the Clonidine group, which was managed with injection Atropine $0.12 \mathrm{mg}$ IV. However, the addition of Clonidine to caudal Bupivacaine did not result in a higher incidence of side-effects compared to caudal Bupivacaine alone.

In the present study, there was no significant motor or sensory blockade 4 hours post-operatively. The number of children in group $C$ requiring rescue analgesia in the first 24 hours was only six which is significantly less, when compared to group B in which as many as 12 children needed rescue analgesia within the first 24 hours. 
In our study, a dose of $1.5 \mathrm{mg} / \mathrm{kg}$ Clonidine was used, but the significant difference in the sedation scores occurred during the first to ninth hours post-operatively. In another study, addition of $1 \mathrm{mg} / \mathrm{kg}$ of Clonidine with $1 \mathrm{~mL} / \mathrm{kg}$ of $.25 \%$ Bupivacaine had a higher sedation score up to 2 in immediate post-operative period for 1 hour compared with addition of $0.2 \mathrm{mg} / \mathrm{kg}$ of Dexamethason in $1 \mathrm{~mL} / \mathrm{kg}$ of $.25 \%$ Bupivacaine in the caudal block. ${ }^{9}$

Although the direct ventilatory effects of epidural Clonidine are minor, a decreased slope of the ventilatory response to $\mathrm{CO}_{2}$ may detect mild respiratory depression. In addition, obstructive apnea and arterial oxygen desaturation might occur with marked sedation. Penon et al. studied the effects of epidural Clonidine ( $300 \mu \mathrm{g}$ ) on circulation and ventilatory control in seven healthy unpremedicated subjects. After Clonidine injection, arterial blood pressure decreased significantly in all subjects. Heart rate decreased significantly by $10 \%-16 \%$ between 75 and 105 min after injection. The slope of the ventilatory response to $\mathrm{CO}_{2}$ decreased significantly from $2.06 \pm 0.70$ (baseline) to $1.37 \pm 68$, $1.25 \pm 0.65$, and $\pm 1.330 .67 \mathrm{~L} / \mathrm{min} / \mathrm{mm} \mathrm{Hg}$ (mean $\pm S D, P$ less than 0.05 ) at 15,60 , and 120 min. $^{15}$

In this study, we did not find any effects on respiratory rate and $\mathrm{SpO}_{2}$, although sedation was more pronounced in the Clonidine group for the first 2 hours post-operatively.

Based on the findings of our study, adding Clonidine $1.5 \mathrm{mg} /$ $\mathrm{kg}$ to Bupivacaine $0.25 \%$ for caudal anesthesia in children undergoing lower abdominal surgeries prolongs duration of analgesia.

\section{Conclusion}

We conclude that adding Clonidine $1.5 \mathrm{mg} / \mathrm{kg}$ to Bupivacaine $0.25 \%$ for caudal anesthesia in children undergoing lower abdominal surgeries enhances and prolongs post-operative analgesia compared to caudal Bupivacaine $0.25 \%$ alone. This could be a safe and cost-effective alternative to extradural catheter placement for surgical procedures of intermediate duration. Caudal Clonidine also prevents the sympathoadrenegic response during emergence from anesthesia, but may have hemodynamic and sedative effects in the early postoperative period. Clonidine may be the drug of choice to prolong the duration of caudal anesthesia provided by a single injection in children.

\section{Conflict of Interest: None}

\section{References}

1. International association for the study of pain. Pain terms: A list with definitions and notes on usage. Pain
1979; 6: 249-51.

2. Choonara I. Pain relief. Arch Disease Child 1989; 64: 1101-02.

3. Krane E, Tyler DC, Jacobson LE. The dose response of caudal morphine in children. Anesthesiology 1989; 71: 48-52.

4. Naguib M, Sharif AMY, Seraj M et al. Ketamine for caudal analgesia in children: comparison with caudal Bupivacaine. Br J Anaesth 1991; 67: 559-64.

5. Sanders JC. Paediatric regional anaesthesia, a survey of practice in the United Kingdom. Br J Anaesth 2002; 89: 707-10.

6. Ansermino M, Basu R, Vandebeek C et al. Nonopioid additives to local anaesthetics for caudal blockade in children: a systematic review. Paediatr Anaesth 2003; 13: 561-73.

7. De Beer DA, Thomas ML. Caudal additives in children solutions or problems? Br J Anaesth 2003; 90: 487-98.

8. Lee JJ, Rubin AP. Comparison of a Bupivacaine-Clonidine mixture with plain Bupivacaine for caudal analgesia in children. British Journal of Anaesthesia 1994; 72(3): 258-62.

9. Solanki NM, Engineer RS, Patel BR et al. Enhancement of Bupivacaine caudal analgesia using dexamethasone or Clonidine in children undergoing subumbilical surgery, ASJA 2016; 9(2): 274-79.

10. Lloyd Thomas AR. Pain management inpediatric patients. British Journal of Anaesthesia 1990; 64: 85104.

11. Giaefre E. Caudal anesthesia in children. Anesthesiology 1995; 43(3): 281-86.

12. Bonnet F, Boico 0, Rostaing S et al. Clonidine-induced analgesia in postoperative patients: Epidural versus Intramuscular administration. Anesthesiology 1990; 72: 423-27.

13. Bonnet F, Boico O, Rostaing S. Clonidine-induced analgesia in postoperative patients: Epidural versus Intramuscular administration. Anesthesiology 1990; 72: 423-27.

14. Liv N, Bonnet F, Delauway L et al. Partial reversal of the effects of extradural Clonidine by oral Yohimbine in postoperative patients. British Journal of Anaesthesia 1993; 70: 515-18.

15. Dupeyart A, Goujard E, Muret J et al. Transcutaneous $\mathrm{CO} 2$ tension on effects of Clonidine in pediatric caudal analgesia in patients. Pediatric Anesthesia 1998; 8: 145-48.

16. Penon C, Ecoffey C, Cohen SE. Ventilatory response to carbon dioxide after epidural Clonidine injection. Anesthesia Analgesia 1991; 72: 761-64.

Date of Submission: 2018-04-10 Date of Acceptance: 2018-04-19 